\title{
Dose-ranging study of BTI320 in type 2 diabetic patients
}

\author{
David R Luke ${ }^{1,2 *}$, Edith MY Cheng ${ }^{2,3}$, Erin Stokes ${ }^{4}$, Karen Ka Yan Lee ${ }^{2,3}$, Carl W Rausch ${ }^{2,3}$ and Ronald W Harris ${ }^{4}$ \\ ${ }^{1}$ DRL Pharmaceutical Consulting, LLC, Ledyard, CT 06339 \\ ${ }^{2}$ Sugar down Co. Ltd, Tai Po, Hong Kong \\ ${ }^{3}$ Boston Therapeutics, Inc. Lawrence, MA 01843 \\ ${ }^{4}$ Target Health Inc., New York, NY 10016
}

\begin{abstract}
Background/objectives: Current practice is to treat diabetics with oral hypoglycemics, insulin, or a combination of both; these systemic interventions are not without risk. The reduction in glucose excursion is a new therapeutic paradigm with non-systemic interventions which has been suggested to delay diabetic-associated complications. BTI320, derived from galactomannan, is a non-systemic drug to attenuate postprandial glucose excursion by blocking carbohydrate hydrolyzing enzymes within the gastrointestinal tract. Earlier studies of BTI320 have shown decreased glucose excursions with relatively few adverse effects.
\end{abstract}

Subjects/methods: This double-blind, placebo-controlled, 3-period crossover, outpatient study evaluated two different doses of BTI320, $4 \mathrm{~g}$ and $8 \mathrm{~g}$ three times daily before meals, for 7 days in 23 adults with Type 2 diabetes (mean age 54 years, BMI $31.4 \mathrm{~kg} / \mathrm{m}^{2}$ ). The primary endpoint of the response of postprandial glucose excursion was measured by the area under the curve from 0 to 4 hours (PPG-AUC0-4) following a high carbohydrate meal on the final day of dosing in each crossover arm.

Results: The mean ( \pm SD) PPG-AUC0-4 after 7 days of dosing placebo, $4 \mathrm{~g}$, and $8 \mathrm{~g}$ BTI320 were 179.09 $\pm 157.271,146.61 \pm 98.604$, and $179.09 \pm 157.27$ $\mathrm{mmol} / \mathrm{L}^{*} \mathrm{~min}$, respectively, in the intent-to-treat population, demonstrating appreciable effects of $4 \mathrm{~g}$ BTI- 320 compared with placebo. Similar trends were found in the PPG peak glucose levels and time to peak glucose concentrations. Consistent with other studies, the mean glucose serum concentrations at 2 hours following $4 \mathrm{~g}$ BTI320 (7.57 $\pm 1.519 \mathrm{mmol} / \mathrm{L})$ were markedly lower than those following placebo and $8 \mathrm{~g}$ BTI320 $(7.63 \pm 1.826$ and $7.68 \pm 1.711 \mathrm{mg} / \mathrm{dL}$, respectively).

Conclusion: Data from this proof of concept study comparing two doses ( 4 and $8 \mathrm{~g}$ ) of BTI320 demonstrated evidence of $4 \mathrm{~g}$ BTI320 in reducing glucose excursions compared with the $8 \mathrm{~g}$ BTI320 and placebo arms per subject. Whereas these data support other published studies of BTI320 limiting the magnitude of glucose excursion, variables such as rate of glucose absorption, age of the patient, and amount of carbohydrates in each meal, amongst others, require an expanded population in a Phase 3 trial to confirm these findings.

\section{Introduction}

According to a recent World Health Organization report, there are an estimated 422 million adults living with diabetes globally in 2014 [1], and 30.3 million diabetics (9.4\% of the population) in the USA in 2015 [2]. This prevalence is a 2.5 -fold increase in less than 2 decades since an earlier report estimated a global population of 171 million diabetics in 2000 [3], although one could argue that definitions of diabetes have changed over this time course [4]. Diabetes mellitus is a syndrome with significant microvascular and macrovascular complications, such as the triopathies (retinopathy, neuropathy, and nephropathy), as well as cardiovascular disease and early mortality [5]. Further, it is an economic burden with total costs (direct medical costs plus reduction in productivity costs) estimated at \$327 billion in the USA in 2017 [6].

Historically, dating back to almost a century ago, insulin was the primary focus in the control of glucose for the treatment of diabetes mellitus. Exogenous insulin was administered to reduce fasting glucose concentrations in diabetic patients following ingestion of foods with high glycemic indices (GI). In more recent times, diabetes mellitus was differentiated between insulin deficiency (Type 1 diabetes mellitus [T1DM]) and insulin resistance (Type 2 diabetes mellitus [T2DM]) [7]. However, unlike T1DM which is thought to be a metabolic disease, T2DM may be prevented by identifying those with pre-diabetes, defined as impaired glucose tolerance and/or impaired fasting glucose but not meeting the definition of diabetes (typically a post-prandial glucose value (PPG) of $\geq 100 \mathrm{mg} / \mathrm{dL}$ but $\leq 125 \mathrm{mg} / \mathrm{dL}$ ) $[8,9]$, and implementing preventive methodologies such as diet control and exercise [10-12]. In other cases, whereupon T2DM has been diagnosed, patients are treated with oral hypoglycemics and/or insulin.

Data suggest that better control of postprandial glucose excursions (PPGE; rise in serum glucose levels following a meal) may attenuate development of diabetic complications [13], although there has been considerable debate related to direct causality versus underlying conditions such as obesity, exercise inactivity, and age [14-17]. The primary source of glucose in the body is through ingestion of carbohydrates. Since the currently available processed carbohydratecontaining foods consist of higher GI and glycemic loads (GL), are calorie dense and low in dietary fiber, these are rapidly digested and absorbed, resulting in higher PPGE in healthy subjects $[18,19]$. The corollary of this is the use of diabetes-specific formulae of low GI and/ or slowly digestible carbohydrates, low-carbohydrate diets, or timing

${ }^{\star}$ Correspondence to: David R Luke, Senior Medical Consultant, Clinical Development, DRL Pharmaceutical Consulting, LLC, 43 Chriswood Trace, Ledyard, CT 06339 USA, Tel: (860) 608-5296, E-mail: DLuke4@Comcast.net

Key words: BTI320, type 2 diabetes, NIDDM, galactomannans

Received: January 03, 2020; Accepted: January 17, 2020; Published: January 17, 2020 
of the daily carbohydrate meal which results in lower PPGE [20-27], although others have had indeterminate results with these strategies [28-31]. Importantly, the difficulty in the diabetic patient is the inability to process glucose in an efficient manner. Thus, large postprandial glucose spikes chronically overwhelm the systemic pathways to handle glucose which initiates a cyclical cascade towards the development of obesity, oxidative stress, inflammation, end-organ damage, and cardiovascular disease [32-35].

BTI320 (SUGARDOWN', PAZ320; Boston Therapeutics, Inc., Lawrence, MA, USA) is a non-absorbable chewable complex polysaccharide that supports healthy blood sugar by predominately suppressing PPGE, slowing down the rate of glucose excursion, as well as reducing the absolute amount of glucose absorbed, thereby preventing hyperglycemia without the risk of hypoglycemia. Chemically, it is a straight backbone chain composed of (1-4)-linked$\beta$-D-mannopyranosyl residues with side-branching $a$-Dgalactopyranosyl residues; the formulation of BTI320 and its matching placebo is outlined in (Table 1). BTI320 has been identified through NMR to consist of 2 types of galactomannans, GM $\alpha$ and GM $\beta$ in a 1:4 molar ratio with other constituents including sorbitol. This formulation, when administered as a chewable tablet, has been shown in various clinical studies to reduce postprandial blood glucose level by reducing the amount of glucose available for intestinal absorption. The mechanism of the effect on blood glucose is not fully understood. It is hypothesized that BTI320 has the capacity to induce moderate inhibition on carbohydrate-hydrolyzing enzymes (i.e., $\alpha$-glucosidase, amylase) in the gastrointestinal tract (GIT), hampering the fast and extensive breakdown and absorption of dietary carbohydrates (glucose). Findings from previous studies suggest that treatment with BTI320 was safe and effective in controlling postprandial glucose excursions relative to placebo with no adverse events of moderate to serious severity [36-38].

We present data from our double-blind, placebo-controlled, doseranging, 3-way cross-over, multiple-dose, single center outpatient study of the postprandial glucose responses following a test meal containing approximately $80 \mathrm{~g}$ carbohydrates, alone (placebo) and with two different doses of BTI320, in T2DM patients.

\section{Methods}

\section{Study subjects}

This double-blind, placebo-controlled, randomized-sequence, three-period crossover study was conducted at one study site on
Long Island, New York. A total of 24 subjects with T2DM, treated with oral and/or injectable hypoglycemics, were enrolled in the study. This outpatient study evaluated PPG responses of test meals containing approximately $80 \mathrm{~g}$ carbohydrates consumed with BTI320 or drug-free placebo, three times daily, prior to each meal for 7 days per treatment arm. To preserve blinding, subjects were randomized to ingest 2 placebo tablets, one $4 \mathrm{~g}$ active and 1 placebo tablet, or two $4 \mathrm{~g}$ active tablets in each of the three 7-day study intervals. Since BTI320 is non-absorbable and the effect is immediate, no washout periods were scheduled between treatment periods. The study was approved by the Schulman Committee for the Protection of Human Subjects (now Advarra following the merge between Schulman and Chesapeake Institutional Review Boards) and conducted according to the Declaration of Helsinki [39].

Eligibility criteria included: males or females between $25-75$ years of age, maintained on a stable dose of metformin for at least 3 months prior to the screening visit, body mass index (BMI) between 25 and 40 $\mathrm{kg} / \mathrm{m}^{2}, \mathrm{HbAlc}$ values between 6 and $9 \%$, a fasting serum glucose $\geq 126$ and $<180 \mathrm{mg} / \mathrm{dL}$ ( $\geq 7.0$ and $<10.0 \mathrm{mmol} / \mathrm{L}$ ), and a diagnosis of Type 2 diabetes mellitus with one of the following criteria: 2-hour serum glucose $\geq 200 \mathrm{mg} / \mathrm{dL}$ ( $\geq 11.1 \mathrm{mmol} / \mathrm{L}$ ) during PPGE assessment, or a random serum glucose $\geq 200 \mathrm{mg} / \mathrm{dL}(\geq 1.1 \mathrm{mmol} / \mathrm{L})$ in subjects with classic symptoms of hyperglycemia or hyperglycemic crisis (American Diabetes Association [40], 2011). Written informed consent was obtained from all participants prior to any trial-related activities.

Subjects were excluded from study due to underlying cardiovascular, peripheral vascular, or cerebrovascular disease, determined by the Investigator as clinically significant; abnormal liver function (AST or ALT $>1.5$ times the upper limit of normal [ULN]), renal dysfunction (estimated glomerular filtration rate $[\mathrm{eGFR}]<60 \mathrm{~mL} / \mathrm{min}$, estimated by the Modification of Diet in Renal Disease [41], abnormal hematologic tests (hemoglobin $<10 \mathrm{~g} / \mathrm{dL}$ ), any gastrointestinal disease affecting absorption of carbohydrates or glucose, antidiabetic medications other than metformin; any other medications (e.g., steroids, hormones) which can affect glycemic control, lactating or pregnant female subjects, those with illicit drug abuse or alcoholism, or participation in another clinical or investigational study within the last 30 days prior to screening. Further, subjects were excluded from the evaluability population if they failed to achieve a blood glucose $>140 \mathrm{mg} / \mathrm{dL}(>7.8$ $\mathrm{mmol} / \mathrm{L}$ ) during the baseline PPGE assessment.

The primary objective was to evaluate the effects of study drug by the area under the concentration-time curve (AUC) of postprandial

Table 1. Formulations of BTI320 and its color- and taste-matched placebo

\begin{tabular}{|c|c|c|c|}
\hline \multicolumn{4}{|c|}{ Placebo Formulation } \\
\hline Ingredients & Chemical Name & Appearance & Amount per tablet \\
\hline Kaolin & $\sim \mathrm{Al}_{2} \mathrm{Si}_{2} \mathrm{O}_{5}(\mathrm{OH})_{4}$ & White to light yellow powder & $13.33 \%$ \\
\hline Sorbitol & $\mathrm{C}_{6} \mathrm{H}_{14} \mathrm{O}_{6}$ & White powder & $82.95 \%$ \\
\hline Malic Acid & $\mathrm{C}_{4} \mathrm{H}_{6} \mathrm{O}_{5}$ & White powder & $0.37 \%$ \\
\hline Magnesium Stearate & $\mathrm{Mg}\left(\mathrm{C}_{18} \mathrm{H}_{35} \mathrm{O}_{2}\right)_{2}$ & White powder & $1.6 \%$ \\
\hline Natural Food Colors: Carmine & N/A & Pink powder & $0.1 \%$ \\
\hline Flavor & N/A & White powder & $1.65 \%$ \\
\hline \multicolumn{4}{|c|}{ BTI320 Formulation } \\
\hline Ingredients & Chemical Name & Appearance & Amount per tablet \\
\hline Mannan Polysaccharides (SFR and M800) & {$\left[{ }_{1-6}\right.$ alpha-D-Xn- $\left\{\left({ }_{1-4}\right)\right.$-beta-D-mannose $\left.\}\right] n$} & White to cream powder & $\sim 40 \%$ \\
\hline Sorbitol & $\mathrm{C}_{6} \mathrm{H}_{14} \mathrm{O}_{6}$ & White powder & $\sim 57.08 \%$ \\
\hline Malic Acid & $\mathrm{C}_{4} \mathrm{H}_{6} \mathrm{O}_{5}$ & White powder & $\sim 0.20 \%$ \\
\hline Magnesium Stearate & $\mathrm{Mg}\left(\mathrm{C}_{18} \mathrm{H}_{35} \mathrm{O}_{2}\right) 2$ & White powder & $\sim 1 \%$ \\
\hline Natural Food Colors: Carmine & N/A & Pink powder & $\sim 0.02 \%$ \\
\hline Flavor & N/A & White powder & $\sim 1.2 \%$ \\
\hline
\end{tabular}


serum glucose levels from time 0-4 hr (PPG-AUC0-4) when taken before a standard meal of white rice in subjects with T2DM maintained on daily metformin monotherapy. Secondary objectives were the peak PPG, defined as the maximal glucose concentration during the excursion (PPG-C $\mathrm{C}_{\max }$ ), the time to maximal glucose concentration (PPG- $\mathrm{T}_{\max }$ ), and the difference in the glucose concentration at 2 hours (PPG-CGLUCOSE-2hr) during the PPGE assessment from baseline. Post-hoc objectives were based on previous literature on the evaluation of the outcome of responders in this study [42-44].

\section{Randomization and treatments}

After the screening visit and enrollment, subjects were instructed to return for a morning visit (Visit 1) in a fasting state and without taking their metformin dose. A fasting blood glucose concentration was obtained prior to the administration of two blinded placebo tablets, and then the PPGE commenced immediately with the ingestion of a standardized meal ( $250 \mathrm{~g}$ white rice [Uncle Ben's Ready Basmati Rice ${ }^{\oplus}$, MARS Food US, LLC, Rancho Domingues, CA, USA, consisting of approximately 403 calories and $78.8 \mathrm{~g}$ carbohydrates]). PPGE was calculated from blood samples that were obtained at 15-minute intervals for 2 hours, then every 30 minutes over the next two hours (blood samples for glucose measurement at $0,15,30,45,60,75,90$, $105,120,150,180,210$, and 240 minutes after drug administration). These observed data were used for verification of the inclusion/ exclusion criteria and not for final analysis. At Visit 2, subjects were then randomized to 1 of 6 treatment visit sequences of placebo, $4 \mathrm{~g}$ dose, or $8 \mathrm{~g}$ dose of BTI320 with each meal. The study site dispensed a one-week supply of the randomized blinded medication, which the subjects took immediately before all daily meals until the next visit. After this 7-day regimen, subjects returned to the clinic in a fasting state without taking their usual dose of metformin for Visit 3. The subjects were administered the treatment assigned at the baseline visit (Visit 2) and PPGE was measured over 240 minutes, using the same method as the baseline visit. The study site provided the subjects with a oneweek supply of a new randomized treatment arm, which they again took immediately prior to meals until Visit 4. PPGE evaluations were repeated during Visits 4 and 5 with alternate treatments according to individual randomizations. Based upon the randomization code, each subject had PPGE assessments after each of the three treatments (4 g BTI320, 8 g BTI320, and placebo) in random order. Fasting blood glucose finger-stick measurements were also obtained at each visit. Subject participation was complete after Visit 5. Safety assessments, including clinical laboratory results, vital sign measurements, physical examinations, and adverse events were collected throughout the study period until follow-up.

\section{Determination and measurement of serum glucose concentrations}

Standard universal precautions were used for collecting blood samples in appropriate tubes provided by ACM Global Central Laboratory (Rochester, NY, USA) in accordance with CLSI guidelines for specimen collection. Serum glucose samples were prepared by inverting tiger-top (serum separator) tubes eight (8) times, allowing blood to clot upright at room temperature for 30 minutes, and then centrifuged for 10 minutes at $1800 \mathrm{~g}$ or until a complete barrier was formed. HbAlc samples were inverted 8 times in lavender tubes containing Na-EDTA and the samples were not centrifuged. Serum glucose and HbAlc EDTA whole blood samples were shipped at ambient temperature overnight to the ACM Global Central Laboratory, whereupon the serum glucose samples were analyzed with a hexokinase, Stein G-6-PD, endpoint methodology and HbAlc samples were analyzed using turbidimetric methodology.

\section{Statistical analyses}

Serum glucose concentrations obtained for each blood sample were used for the 13 time points of each 4-hour test session. For each subject, the incremental area under the 240-minute serum glucose response curve (AUC GLUCOSE) for each visit was calculated using the trapezoidal rule:

$$
\begin{aligned}
& \text { iAUC }=1 / 2 \Sigma \_(\mathrm{i}=1) \wedge \mathrm{n} \_\left(\mathrm{X} \_(\mathrm{i}-1)\right) \times\left(\mathrm{Y} \_(\mathrm{i}-1)+\mathrm{Y} \_\mathrm{i}\right) \\
& =1 / 2\left[\mathrm{X} \_0 \times\left(\mathrm{Y} \_0+\mathrm{Y} 1\right)+\mathrm{X} 1 \times\left(\mathrm{Y} \_1+\mathrm{Y} \_2\right)+\ldots+\mathrm{X} \_(\mathrm{n}-1) \times\left(\mathrm{Y} \_(\mathrm{n}-1)\right.\right. \\
& \left.\left.+\mathrm{Y} \_\mathrm{n}\right)\right]
\end{aligned}
$$

where $\mathrm{Xi}$ is the time in minutes and Yi denotes the actual observed serum glucose concentration $(\mathrm{mg} / \mathrm{dL})$ minus the fasting plasma glucose concentration on that day $[45,46]$. No formal sample size calculation was performed for this pilot study. Twenty-four subjects were considered sufficient to provide adequate preliminary information about the postprandial serum and interstitial glucose levels in subjects with T2DM maintained on metformin after administration of BTI320 with a standard rice meal.

\section{The study populations were identified as:}

1. Intent-to-treat Population (ITT) comprised of all subjects who received at least one dose of BTI320 or placebo after randomization. This was the primary population for analysis.

2. Safety Population: The safety population was identical to the ITT population in this study. All safety analyses were performed on this population.

3. Per Protocol (PP) population: Subjects who receive at least 3 days of BTI320 and met all Inclusion/Exclusion criteria (data not shown).

The primary efficacy variable was PPG-AUC0-4, and secondary efficacy variables were peak postprandial blood glucose (PPG-C ${ }_{\max }$ ), time to peak postprandial blood glucose (PPG- $\mathrm{T}_{\max }$ ), and the difference in baseline glucose concentration at 2 hours (PPG-CGLUCOSE-2hr) during the PPGE assessment in the ITT population.

A crossover analysis of variance (ANOVA) test was used to check if there was a statistically significant difference in the PPG-AUC0-4 means among the three treatment arms. If a statistically significant effect exists, each dose of BTI320 and the placebo were individually compared to identify the difference relative to specific parameter. Treatment, sequence, period, and carryover effects were also considered in the crossover ANOVA statistical analysis. The 95\% confidence interval (CI) for the treatment difference that shows the treatment differ at most is provided in the result section, such point estimates show where the potential treatment effect lies. Responder analysis was also performed ad hoc with all efficacy variables. A responder was defined by a reduction in PPGE, despite the reduction being not significant. A p-value from the two-sided test of $\leq 0.05$ was considered statistically significant.

Descriptive statistics, namely sample size (n), mean, standard deviation, median, and range for continuous variables, count and percentage for categorical variables, were provided. Clinical laboratory results (clinical chemistry, hematology, coagulation, and urinalysis) were summarized with descriptive statistics at Visit 1 and at the end of study and also the change from screening to the end of the study. 


\section{Results}

A total of 48 subjects were screened, 24 subjects were eligible for enrolment, and 23 subjects participated and completed the study, representing the safety/ITT populations. One subject who received only placebo at the baseline visit was excluded from the ITT analyses due to a voluntary withdrawal (i.e., $\mathrm{N}=23$ ).

\section{Demographics}

In this study, both safety and ITT populations are identical, where the mean age for the 23 subjects was $53.7 \pm 9.6$ years (range $35-72 \mathrm{yr}$; median $52.0 \mathrm{yr}$ ). The majority was male and identified as not Hispanic or Latino. The safety population was comprised of 12 White subjects (52.2\%),10 Black subjects (43.5\%), and 1 (4.3\%) Native American subject. All subjects were diagnosed with T2DM and on a stable regimen of metformin for at least 3 months prior to the screening visit. There were no remarkable findings on physical examination, and all had normal end-organ functions except for 3 subjects with marginally lower renal function as measured by estimated glomerular function rate (eGFR; 58,58 , and $55 \mathrm{~mL} / \mathrm{min} / 1.73 \mathrm{~m}^{2}$ ). Baseline laboratory values were within normal limits for all subjects. Mean $( \pm$ SD) baseline fasting glucose levels prior to each PPGE were $7.06 \pm 1.359$ (range, 4.6 - 9.4), $7.31 \pm 1.723$ (range, $5.6-12.4$ ), $7.14 \pm 1.387$ (4.1 - 10.6), and $7.11 \pm 1.354$ (range, $5.2-9.8$ ) $\mathrm{mmol} / \mathrm{L}$ on Days $1,8,15$, and 22, respectively (recall: drug treatment was initiated after the Day 1 fasting glucose level). Eleven subjects (46\%) had fasting blood glucose levels lower than the eligibility criteria for Type 2 diabetes mellitus on Day 1; none had a fasting glucose greater than $180 \mathrm{mg} / \mathrm{dL}(>10.0 \mathrm{mmol} / \mathrm{L})$ at baseline. By definition, those with fasting blood glucose levels $<126$ $\mathrm{mg} / \mathrm{dL}(<7.0 \mathrm{mmol} / \mathrm{L})$ were ineligible for the per protocol population analysis. We present herein the data from all 23 subjects independent of the baseline fasting glucose levels on Day 1 (Table 2). Whereas the remaining number of tablets were counted at each visit to the clinic, compliance was not captured in this study.

\section{Efficacy analysis}

The primary efficacy endpoint of PPG-AUC0-4 was evaluated for each study arm and the statistical analysis is presented in (Table 3). Using traditional statistics as stipulated in the Statistical Analysis Plan (SAP), no statistical differences were observed between placebo and either dose of BTI320. On average, the BTI320 $4 \mathrm{~g}$ group showed $32.48\left(\mathrm{mmol} / \mathrm{L}^{\star} \mathrm{min}\right)$ reduction in the PPG-AUC0-4 compared to the

Table 2. Demographics

\begin{tabular}{|c|c|c|c|}
\hline Demographic & & $\begin{array}{l}\text { ITT population } \\
(\mathrm{N}=23)\end{array}$ & $\begin{array}{c}\text { CE population } \\
\mathrm{N}=17)\end{array}$ \\
\hline \multirow[t]{2}{*}{ Age (years) } & Mean (SD) & $53.7(9.6)$ & $53.3(9.2)$ \\
\hline & Range & $35-72$ & $42-72$ \\
\hline \multirow[t]{2}{*}{ Sex } & M & $17(73.9 \%)$ & $13(76.5 \%)$ \\
\hline & $\mathrm{F}$ & $6(26.1 \%)$ & $4(23.5 \%)$ \\
\hline \multirow[t]{2}{*}{ BMI $\left(\mathrm{kg} / \mathrm{m}^{2}\right)$} & Mean (SD) & $31.4(3.5)$ & $31.6(3.4)$ \\
\hline & Range & $25-38$ & $26-38$ \\
\hline \multirow[t]{2}{*}{ Weight (lb) } & Mean (SD) & $212.1(37.7)$ & $215.5(37.2)$ \\
\hline & Range & $138-305$ & $170-305$ \\
\hline \multirow[t]{2}{*}{ Height (in) } & Mean (SD) & $68.7(3.7)$ & $69.1(3.9)$ \\
\hline & Range & $62-76$ & $62-76$ \\
\hline \multirow[t]{3}{*}{ Race (\%) } & White & $12(52.2 \%)$ & $8(47.1 \%)$ \\
\hline & Black & $10(43.5 \%)$ & $8(47.1 \%)$ \\
\hline & Native American & $1(4.3 \%)$ & $1(5.9 \%)$ \\
\hline \multirow[t]{2}{*}{ HbAlc (\%) } & Mean (SD) & $7(0.7)$ & $7.2(0.7)$ \\
\hline & Range & $6.1-8.3$ & $6.2-8.3$ \\
\hline
\end{tabular}

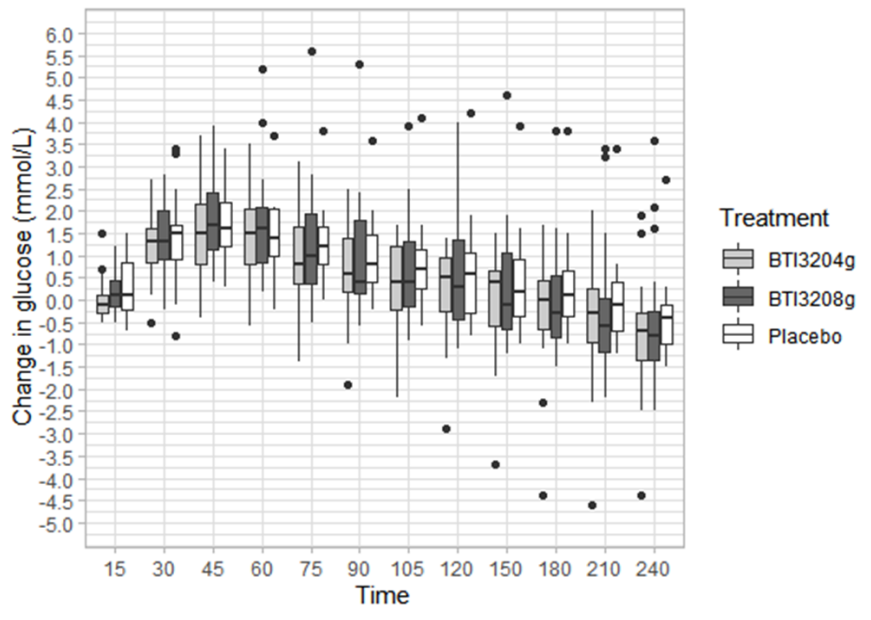

Figure 1. Normalized postprandial blood glucose levels $(\mathrm{mg} / \mathrm{dL})$ in all treatment groups. The boxplot shows the postprandial glucose distribution between treatment groups for up to 4 hours post-meal. All subjects have similar postprandial glucose (PPG) excursions within the first hour. Both BTI320 $4 \mathrm{~g}$ and $8 \mathrm{~g}$ treated patients have lower PPG median from 75 mins to 4 hours post-meal, suggesting the BTI320 treated groups either have quicker glucose recovery to baseline level (i.e., pre-meal), reduction in the amount of glucose absorbed, slowing down the glucose excursion rate and/or reduction in the peak glucose level during the observation period. The black dots represent the outliers with out of range glucose levels ( $>2$ SD from the mean).

placebo group (179.09 $\left.\mathrm{mmol} / \mathrm{L}^{*} \mathrm{~min}\right)$. The mean PPG-C $\mathrm{max}_{\max }$ and time to $\mathrm{C}_{\max }$ during the PPGE were similar amongst treatment groups. Interestingly, the mean glucose concentration at 2 hours was markedly lower in the $4 \mathrm{~g}$ BTI320 treatment group $(7.57 \pm 1.519 \mathrm{mmol} / \mathrm{L})$ compared with placebo $(7.63 \pm 1.826 \mathrm{mmol} / \mathrm{L})$ and the high dose $(8$ g) treatment group $(7.68 \pm 1.711 \mathrm{mmol} / \mathrm{L})$. The mean amplitude of glycemic excursion (MAGE), mean post-prandial maximum glucose (MPMG), mean blood glucose during the 4 hour PPGE period (MBG), standard deviation (SD), and coefficient of variation (CV) (\%) are indicative of post-meal glucose variability; both the BTI320 $4 \mathrm{~g}$ and $8 \mathrm{~g}$ treated groups have lower post-meal glucose variability (with 95\% CI) when compared to the placebo treated group (Table 3).

Despite the small sample size, results highlight the potential effect of $4 \mathrm{~g}$ BTI320 in reducing both PPG-AUC0-4 responses as well as the glucose variability compared with placebo. On average, the BTI320 treated groups ( $4 \mathrm{~g}$ and $8 \mathrm{~g}$ ) showed lower median glucose responses up to 4 hours post-meal (Figure 1). Since the manifestation of diabetes is related to the individual's diet and lifestyle, a combination of personalised medicine and whole population medicine may be needed to improve the chronic condition on an individual basis. Overall, over $60 \%$ of the BTI320-treated patients ( $4 \mathrm{~g}$ and $8 \mathrm{~g}$ ) have a reduction in their PPG-AUC0-4 compared to their respective baselines. Body weights dropped by a mean of 1.83 and 1.11 pounds in the 4 and 8 g BTI320 arms, respectively, compared with a mean increase of 0.5 pounds in the placebo arm. Similarly, BMI dropped in the treated arms $\left(0.29\right.$ and $0.17 \mathrm{~kg} / \mathrm{m}^{2}$ for 4 and $8 \mathrm{~g}$ BTI320, respectively), and systolic and diastolic blood pressures were reduced in the treated arms compared with the placebo arm (Table 4). HbAlc data were similar between the three treatment arms likely due to the relatively short treatment regimens. These data are consistent and supportive of results observed from previous clinical studies with BTI320.

\section{Safety analysis}

There were no adverse events reported in the short-term dosing intervals of BTI320 nor placebo arms. Further, apart from expected 
Table 3. Efficacy variables in the ITT population

\begin{tabular}{|c|c|c|c|c|c|c|c|c|c|}
\hline Variables & Study & $\begin{array}{c}\text { Treatment } \\
\text { Arm }\end{array}$ & Mean & $\mathbf{n}$ & SD & $\begin{array}{l}\text { Placebo - } \\
\text { Treatment }\end{array}$ & \multicolumn{2}{|c|}{$95 \% \mathrm{CI}$} & p-value \\
\hline \multirow{3}{*}{1 hour's PPG AUC $(\mathrm{mmol} / \mathrm{L} * \min )$} & \multirow{3}{*}{ SD-002 } & $4 \mathrm{~g}$ & 55.47 & 23 & 31.720 & 8.22 & -11.42 & 27.86 & 0.40 \\
\hline & & $8 \mathrm{~g}$ & 63.75 & 23 & 31.120 & -0.07 & -19.53 & 19.4 & 1.00 \\
\hline & & Placebo & 63.68 & 23 & 34.319 & & & & \\
\hline \multirow{3}{*}{2 hour's PPG AUC $(\mathrm{mmol} / \mathrm{L} * \min )$} & \multirow{3}{*}{ SD-002 } & $4 \mathrm{~g}$ & 107.41 & 23 & 68.068 & 18.78 & -23.87 & 61.43 & 0.38 \\
\hline & & $8 \mathrm{~g}$ & 128.97 & 23 & 89.860 & -2.77 & -52.03 & 46.49 & 0.91 \\
\hline & & Placebo & 126.20 & 23 & 75.277 & & & & \\
\hline \multirow{3}{*}{3 hour's PPG AUC $(\mathrm{mmol} / \mathrm{L} * \min )$} & \multirow{3}{*}{ SD-002 } & $4 \mathrm{~g}$ & 132.46 & 23 & 85.926 & 28.37 & -33.85 & 90.59 & 0.36 \\
\hline & & $8 g$ & 163.53 & 23 & 143.270 & -2.71 & -81.40 & 75.99 & 0.95 \\
\hline & & Placebo & 160.83 & 23 & 120.578 & & & & \\
\hline \multirow{3}{*}{4 hour's PPG AUC $(\mathrm{mmol} / \mathrm{L} * \mathrm{~min})$} & \multirow{3}{*}{ SD-002 } & $4 \mathrm{~g}$ & 146.61 & 23 & 98.604 & 32.48 & -45.53 & 110.48 & 0.41 \\
\hline & & $8 \mathrm{~g}$ & 179.09 & 23 & 157.270 & -7.14 & -108.66 & 94.38 & 0.89 \\
\hline & & Placebo & 179.09 & 23 & 157.271 & & & & \\
\hline \multirow{3}{*}{ MAGE (1 hour) } & \multirow{3}{*}{ SD-002 } & $4 \mathrm{~g}$ & 2.01 & 23 & 0.895 & -0.13 & -0.61 & 0.35 & 0.58 \\
\hline & & $8 g$ & 2.16 & 23 & 1.094 & -0.28 & -0.83 & 0.27 & 0.31 \\
\hline & & Placebo & 1.87 & 23 & 0.717 & & & & \\
\hline \multirow{3}{*}{ MAGE ( 2 hour) } & \multirow{3}{*}{ SD-002 } & $4 \mathrm{~g}$ & 1.92 & 23 & 0.775 & -0.01 & -0.46 & 0.43 & 0.96 \\
\hline & & $8 \mathrm{~g}$ & 2.21 & 23 & 1.115 & -0.3 & -0.86 & 0.26 & 0.28 \\
\hline & & Placebo & 1.91 & 23 & 0.726 & & & & \\
\hline \multirow{3}{*}{ MAGE (3 hour) } & \multirow{3}{*}{ SD-002 } & $4 \mathrm{~g}$ & 2.13 & 23 & 0.808 & -0.18 & -0.66 & 0.29 & 0.44 \\
\hline & & $8 \mathrm{~g}$ & 2.30 & 23 & 1.123 & -0.34 & -0.92 & 0.23 & 0.24 \\
\hline & & Placebo & 1.95 & 23 & 0.787 & & & & \\
\hline \multirow{3}{*}{ MAGE (4 hour) } & \multirow{3}{*}{ SD-002 } & $4 \mathrm{~g}$ & 2.32 & 23 & 0.889 & -0.23 & -0.72 & 0.25 & 0.34 \\
\hline & & $8 \mathrm{~g}$ & 2.41 & 23 & 0.904 & -0.32 & -0.82 & 0.17 & 0.19 \\
\hline & & Placebo & 2.08 & 23 & 0.743 & & & & \\
\hline \multirow{3}{*}{$\begin{array}{l}\text { MPMG }(\mathrm{mmol} / \mathrm{L}) \\
(4 \text { hours })\end{array}$} & \multirow{3}{*}{ SD-002 } & $4 \mathrm{~g}$ & 8.59 & 23 & 1.503 & 0.03 & -0.89 & 0.94 & 0.95 \\
\hline & & $8 \mathrm{~g}$ & & & & 0.88 & -0.79 & 0.91 & 0.88 \\
\hline & & Placebo & 8.62 & 23 & 1.570 & & & & \\
\hline \multirow{3}{*}{$\begin{array}{l}\text { MBG }(\mathrm{mmol} / \mathrm{L}) \\
(4 \text { hours })\end{array}$} & \multirow{3}{*}{ SD-002 } & $4 \mathrm{~g}$ & 7.75 & 23 & 1.367 & -0.03 & -0.91 & 0.84 & 0.94 \\
\hline & & $8 \mathrm{~g}$ & & & & -0.03 & -0.9 & 0.84 & 0.94 \\
\hline & & Placebo & 7.72 & 23 & 1.568 & & & & \\
\hline \multirow{3}{*}{$\begin{array}{l}\text { SD } \\
\text { (4 hours) }\end{array}$} & \multirow{3}{*}{ SD-002 } & $4 \mathrm{~g}$ & 0.94 & 23 & 0.301 & -0.1 & -0.26 & 0.07 & 0.24 \\
\hline & & $8 \mathrm{~g}$ & 1.03 & 23 & 0.36 & -0.19 & -0.37 & 0 & 0.05 \\
\hline & & Placebo & 0.85 & 23 & 0.245 & & & & \\
\hline \multirow{3}{*}{$\begin{array}{l}\mathrm{CV}(\%) \\
\text { (4 hours) }\end{array}$} & \multirow{3}{*}{ SD-002 } & $4 \mathrm{~g}$ & 12.41 & 23 & 4.339 & -1.04 & -3.53 & 1.45 & 0.4 \\
\hline & & $8 \mathrm{~g}$ & 13.52 & 23 & 4.338 & -2.15 & -4.64 & 0.34 & 0.09 \\
\hline & & Placebo & 11.37 & 23 & 4.025 & - & - & - & - \\
\hline
\end{tabular}

Table 4. Secondary output summary in the ITT population

\begin{tabular}{|c|c|c|c|c|c|c|c|c|c|}
\hline Variables & Study & $\begin{array}{l}\text { The Last } \\
\text { Treatment }\end{array}$ & Mean & $\mathbf{n}$ & SD & $\begin{array}{l}\text { The Last } \\
\text { treatment } \\
\text { (Placebo - }\end{array}$ & \multicolumn{2}{|c|}{$95 \%$ CI } & \multirow[t]{2}{*}{ p-value } \\
\hline Age (year) & SD-002 & All & 53.70 & 23 & 9.583 & & & & \\
\hline \multirow{3}{*}{$\begin{array}{l}\text { Body weight change (lb) } \\
\text { (last allocated treatment - baseline) }\end{array}$} & \multirow{3}{*}{ SD-002 } & $4 \mathrm{~g}$ & -1.83 & 6 & 2.714 & 2.33 & 0.16 & 4.50 & 0.04 \\
\hline & & $8 \mathrm{~g}$ & -1.11 & 9 & 1.764 & 1.61 & 0.19 & 3.03 & 0.03 \\
\hline & & Placebo & 0.50 & 8 & 0.756 & & & & \\
\hline \multirow{3}{*}{$\begin{array}{l}\text { BMI (last allocated treatment - } \\
\text { baseline) }\end{array}$} & \multirow{3}{*}{ SD-002 } & $4 \mathrm{~g}$ & -0.29 & 6 & 0.438 & 0.36 & 0.01 & 0.70 & 0.04 \\
\hline & & $8 \mathrm{~g}$ & -0.17 & 9 & 0.265 & 0.24 & 0.03 & 0.45 & 0.03 \\
\hline & & Placebo & 0.07 & 8 & 0.103 & & & & \\
\hline \multirow{3}{*}{$\begin{array}{l}\text { SBP (last allocated treatment - } \\
\text { baseline) }\end{array}$} & \multirow{3}{*}{ SD-002 } & $4 \mathrm{~g}$ & -9.00 & 6 & 14.478 & 14 & -3.12 & 31.12 & 0.10 \\
\hline & & $8 \mathrm{~g}$ & -9.22 & 9 & 15.635 & 14.22 & -1.48 & 29.92 & 0.07 \\
\hline & & Placebo & 5.00 & 8 & 14.599 & & & & \\
\hline \multirow{3}{*}{$\begin{array}{c}\text { DBP (last allocated treatment - } \\
\text { baseline) }\end{array}$} & \multirow{3}{*}{ SD-002 } & $4 \mathrm{~g}$ & -4.50 & 6 & 3.391 & 4.75 & 0.08 & 9.42 & 0.047 \\
\hline & & $8 \mathrm{~g}$ & -6.33 & 9 & 9.474 & 6.58 & -1.1 & 14.27 & 0.09 \\
\hline & & Placebo & 0.25 & 8 & 4.334 & & & & \\
\hline \multirow{3}{*}{$\begin{array}{c}\text { HbAlc (\%) } \\
\text { (last allocated treatment - baseline) }\end{array}$} & \multirow{3}{*}{ SD-002 } & $4 \mathrm{~g}$ & -0.32 & 6 & 0.538 & 0.23 & -0.26 & 0.72 & 0.33 \\
\hline & & $8 \mathrm{~g}$ & 0.07 & 9 & 0.424 & -0.15 & -0.54 & 0.23 & 0.41 \\
\hline & & Placebo & -0.09 & 8 & 0.304 & & & & \\
\hline
\end{tabular}


changes in serum glucose levels, there were no significant changes in clinical laboratory parameters.

\section{Discussion}

The present study compared two different doses of BTI320 vs. placebo in attenuating the PPGE in T2DM. The primary endpoint was the difference between these active doses ( 4 and $8 \mathrm{~g}$ ) and placebo as measured by the AUC of glucose levels over a four-hour period following ingestion of a standard white rice meal ( $~ 80 \mathrm{~g}$ carbohydrates). Data showed that on average, the placebo group had a higher mean change in PPG up to 4 hrs post-meal. Data also showed that the placebo group tended to have a higher PPGE whereas those in the low dose (4 g) and high dose (8 g) groups tended to have a lower PPGE compared to the fasting state, suggesting that BTI320 is effective in limiting postprandial excursion. This is consistent with the findings observed in 3 published studies conducted in obese, but otherwise healthy volunteers, prediabetics, and T2DM patients where significant effects associated with various doses of BTI320 were observed [36-38]. With the understanding that no one drug will be effective for all individuals, whether it is diabetes $[37,38]$ or other chronic conditions (e.g., cancer, obesity, hyperlipidemia, or analgesia), each individual subject was his/ her own control due to glucose variability, which is controlled by factors not only diet-based but also other medications and hormonal factors. Further, diurnal variability influences glucose levels on a daily basis [47]. The change in PPGE observed in this study was not compared to the reading obtained from the first baseline visit, rather, it was compared to the fasting state of that particular visit. Hence, the change in PPGE is calculated by subtracting the fasting glucose concentration from the actual glucose concentration obtained on that particular day in an attempt to normalize the data between subjects.

The one common denominator amongst all of these studies is the study drug. The active ingredients of BTI320, also known as SUGARDOWN $^{\circ}$ or PAZ320, consist of two forms of galactomannan: galactomannan- $\alpha$ and $-\beta$ with slight modifications in the ratio (Table 1). The current ratio of 1:4 is considered to produce an inhibitory effect on enzymes (e.g., $\alpha$-glucosidase, amylase) in the GIT which hydrolyze carbohydrates, thus slowing glucose absorption into the vascular space.

Table 5. Comparison of BTI $320^{1}$ studies.

\begin{tabular}{|c|c|c|c|c|c|}
\hline Citation & Trask 2013 & Luke 2018-A & Luke 2018-B & Luk 2018 & Current paper \\
\hline ClinicalTrials.gov & NCT02060916 & NCT03375398 & NCT03374501 & NCT02358668 & NCT02135549 \\
\hline Population & T2DM & Healthy obese & Healthy obese & Prediabetes & T2DM \\
\hline $\mathrm{N}$ (active/placebo) & 24 (sequential) & 10 (crossover) & 10 (crossover) & $60(2: 2: 1)$ & 23 (crossover) \\
\hline BMI, $\mathrm{kg} / \mathrm{m}^{2}$ & $25-45$ & $26-29$ & $25-32$ & N/A & $26-38$ \\
\hline Age range, yr & $18-75$ & $26-37$ & $19-56$ & $18-70$ & $35-72$ \\
\hline $\mathrm{HbA}_{1 \mathrm{c}}, \%$ & $\leq 9.0$ & N/A & N/A & $5.7-6.4$ & $6.2-8.3$ \\
\hline BTI $320^{1}$ dose, $g$ & $8 / 16$ & $6 / 12$ & $2 / 4$ & $4 / 8$ & $4 / 8$ \\
\hline Test meal & $75 \mathrm{~g}$ Jasmine rice & Jasmine rice & Sprite $^{\mathrm{TM}}$ & $\begin{array}{l}\text { Shortcakes and soymilk ( } 75.7 \\
\text { g carbohydrates) }\end{array}$ & $\begin{array}{l}\text { Uncle Ben's Basmati Rice } \\
78.8 \text { g carbohydrates }\end{array}$ \\
\hline Time of dosing & 10 min prior to meal & $10 \mathrm{~min}$ prior to meal & 10 min prior to meal & 10 min prior to meal & 10 min prior to meal \\
\hline Duration of assessment & 7 days & Single doses & Single doses & 4 weeks & 3 weeks \\
\hline Primary endpoint & $3 \mathrm{hr} \mathrm{gAUC}^{2}$ and $2 \mathrm{hr}$ gAUC & $2 \mathrm{hr}$ gAUC & $2 \mathrm{hr}$ gAUC & $\begin{array}{l}\text { Change in baseline } \\
\text { fructosamine }\end{array}$ & $4 \mathrm{hr}$ gAUC \\
\hline Blinding & Open-label & Open-label & Open-label & Double-blind & Double-blind \\
\hline Statistical test & $\begin{array}{l}\text { Responder vs. Non- } \\
\text { responders }\end{array}$ & $\begin{array}{l}\text { ANOVA of gAUC and } \\
\text { iAUC }\end{array}$ & ANOVA of gAUC and iAUC & $\begin{array}{l}\text { ANCOVA fructosamine at } \\
4 \text { weeks }\end{array}$ & ANOVA of gAUC \\
\hline Outcome & $\begin{array}{l}40 \% \text { reduction gAUC with } \\
\text { high dose vs. control in high } \\
\text { responders }\end{array}$ & $\begin{array}{l}\mathrm{p} \leq 0.05 \text { dose-dependent } \\
\text { response }\end{array}$ & $\begin{array}{l}\mathrm{p} \leq 0.05 \text { dose-dependent } \\
\text { response }\end{array}$ & $\begin{array}{l}\text { Low-dose reduce } 1,2, \& 3-\mathrm{hr} \\
\text { gAUC and } \mathrm{C}_{\text {max }} . \text { No change in } \\
\text { fructosamine levels }\end{array}$ & $\begin{array}{l}\text { Low-dose }(4 \mathrm{~g}) \text { reduce } 1,2, \\
\& \text { 3-hr gAUC and Cmax. }\end{array}$ \\
\hline $\mathrm{AE}$ & $\begin{array}{l}\text { GI } 26 \%(2 \mathrm{~d} / \mathrm{c}), \mathrm{n}=3 \text { mild } \\
\text { hypoglycemia }\end{array}$ & Mild GI effects $(\mathrm{N}=2)$ & None & $\begin{array}{l}\mathrm{N}=3 \mathrm{~d} / \mathrm{c}-1 \text { due to } \mathrm{SAE} \\
\text { (osteosarcoma) \& } 1 \text { due to GI }\end{array}$ & None \\
\hline
\end{tabular}

${ }^{1}$ Also known as PAZ320 or SUGARDOWN; ${ }^{2}$ gAUC: glucose AUC; ${ }^{3}$ iAUC:insulin AUC
We hypothesized that BTI320 is effective in maintaining the same level of glucose from the breakdown of food products but slows down the process associated with its absorption in the body. Current thought is that high and rapid PPGE results in long-term diabetes-related complications, such as cardiovascular and renal damage, in both Type 1 and 2 diabetic patients [16,48-50]. To date, there have been four studies published which have evaluated BTI320 in Chinese subjects with prediabetes [51], healthy obese subjects [36], and Type 2 diabetics [37]. As depicted in (Table 5), all four studies demonstrated benefit of BTI320 over placebo. In the Trask 2013 study, the Authors compared highdose and low-dose BTI320 versus placebo in T2DM patients. There was a $40 \%$ reduction in glucose AUC (gAUC) compared with placebo following $8 \mathrm{~g}$ BTI320. In our studies, there was a dose-dependent response with BTI320 over placebo [36]. Similarly, low-dose BTI320 ( $4 \mathrm{~g}$ TID) reduced 1,2 , and $3 \mathrm{hr}$ gAUC compared with placebo in the Luk study [51]. Although demographics and study design amongst these published studies are similar to our current study, the potential effect on PPGE reduction observed in this study is not as prominent as those seen in obese, but otherwise healthy (prediabetic) subjects. This could be due to the small sample size which may limit the potential effect of BTI320. In addition, one of the biggest limitations is the fact that the study was performed in an 'out-patient' setting. Along with hypoglycemics and exercise, diet adherence is a hallmark of treatment for Type 2 diabetics [52]. There was no education regarding barriers to diet adherence, counselling on a nutritional plan, nor diet compliance and regulation in the current study - all would allow visualization of the effect of BTI320 in these T2DM patients [53]. Future studies should implement tools (e.g., Continuous Glucose Monitor (CGM), food diaries, mobile tablets/apps which alert the individual on his/her diet) to then be able to focus on the direct effects of interventions [53-56], although we agree that mobile technology needs further validation [57]. One of the strengths of the current study is the cross-over design, allowing each subject to be his/her own baseline, thus eliminating confounding results due to glucose variability. It is interesting to note that although greater doses of BTI320 have been evaluated in prior studies, there appears to be a saturation of dose in all studies and the threshold may be $4-6 \mathrm{~g}$ per meal, which is understandable given the mechanism of action of galactomannans. Indeed, data from the 
current study showed that PPGE reduction is greater in the BTI320 $4 \mathrm{~g}$ compared to both the $8 \mathrm{~g}$ and placebo interventions. BTI320 $4 \mathrm{~g}$ also appeared to be the optimal dosage in attenuating postprandial rise in blood glucose in high risk Chinese prediabetics [51]. A posthoc analysis also reviewed the differences in PPG-AUC from 0-2 hours, as previously demonstrated in the literature [38], for responders modified for AUC rather than Cmax or any other single determination of glucose. There is evidence to suggest that a single point of Cmax is not as accurate as the AUC in pharmacokinetic studies [58]. We applied these same standards to our study in comparison with another which relied on a single point determination (glucose concentration at 2 hours) [37]. Data showed that all subjects in the study responded to BTI320 by having a reduction in PPGE, although some may be small and not significant due to the effect of concomitant diabetes regimen, particularly in those who are managing their conditions adequately ('responders').

When analyzed using a different method, where the change in PPG is defined as the actual glucose concentration minus the fasting glucose concentration, a negative change in glucose from $150 \mathrm{~min}$ post meal was observed, suggesting that the actual measured glucose concentration was lower than the fasting blood glucose concentration. Additionally, when presented in the box plot (Figure 1), the placebo group showed a higher median change across time up to 4 h post meal. The placebo group tended to have a higher PPG excursion whereas those in the low dose $(4 \mathrm{~g})$ and high dose $(8 \mathrm{~g})$ groups tended to have a lower PPG excursion compared to their fasting state, suggesting that BTI320 is effective in limiting PPG increases. Unlike other orally administered antidiabetic drugs used for the treatment of T2DM, BTI320 has not been associated with systemic toxicities. Due to the non-absorbable nature of BTI320, no hypoglycemic episodes were expected, and none were found in this study. BTI320 only acts on the carbohydrate-hydrolyzing enzymes in the GIT to prevent its breakdown into glucose. Thus, BTI320 reduces the rise in postprandial glucose by delaying the timing and the amount absorbed in the GIT. The effect is immediate and BTI320 limits absorption of dietary glucose without interfering with systemic glucose levels. Previous published studies with BTI320 in pre-diabetics and those with T2DM failed to show any clinically significant hypoglycemic events. Similar to other a-glucosidase inhibitors $[19,59]$, the primary complaints of BTI320 were mild to moderate gastrointestinal discomforts such as flatulence and abdominal distress, which appear to be dose-dependent. The current study reported no adverse events, which is also consistent with previous studies with BTI320.

As with all drugs in development, whether small molecules, biologics, or botanicals, the efficacy must be balanced with treatmentemergent adverse events (TEAE) and/or drug-associated toxicities. Throughout each stage of drug development (pre-clinical, Phases 1, 2 , and 3 ), one must continuously evaluate the risk vs. benefit ratio. In the case of BTI320 and other non-absorbable/nonsystemic drugs (e.g., saponins) [60,61]; bile acid sequestrant polymers [62]; and other a-glucosidase inhibitors [63], amongst others), this becomes a relatively uncomplicated process as toxicity evolves from drug and is isolated to a single compartment - the GIT - and generally not hampered by systemic drug-drug interactions and negative effects to primary end-organs such as the liver and kidneys [64]. Unlike acarbose and other a-glucosidase inhibitors [65], toxicity to end-organs has not been observed with BTI320, only flatulence and diarrhea which are thought to be limited to the gastrointestinal tract and not systemically manifested. Even though these adverse events have been noted in previous studies with BTI320, no adverse events were found in the current study.

It is tempting to speculate that we found a ceiling effect of BTI320 in type 2 diabetics. Doses, ranging from $2.6 \mathrm{~g}$ to $16 \mathrm{~g}$ [36,37], were examined in prior studies. To assess any ceiling (or floor) effect, we reviewed each study separately and summarize herein. Trask and co-workers (2013) evaluated $8 \mathrm{~g}$ (low dose) and $16 \mathrm{~g}$ (high dose) BTI320 in type 2 diabetics and found the CGM readings of low and high dose interventions were indistinguishable and the PPGE curves were clearly lower than those found in the placebo group (Table 6). Similarly, this finding was duplicated with either $6 \mathrm{~g}$ or $12 \mathrm{~g}$ BTI320 compared with placebo which showed pronounced glucose excursions [36]. In the same paper, $2.6 \mathrm{~g}$ and $5.2 \mathrm{~g}$ BTI320 resulted in virtually superimposable PPGE curves which were much lower than the placebo group. Furthermore, a study evaluating the efficacy and safety of BTI320 on postprandial hyperglycemia in Chinese prediabetics also showed significantly lower postprandial glucose AUC values at 1, 2, and 3 hours, as well as significant attenuation in several CGM glycemic variability parameters amongst subjects receiving low dose BTI320 (4g) for 16 weeks compared with baseline values and those measured

Table 6. PPG-AUC ${ }_{0-2}$ at low-dose and high-dose BTI320 relative to placebo group

\begin{tabular}{|c|c|c|c|c|c|c|}
\hline Responders & Subject & $\begin{array}{c}\text { Placebo } \\
\text { AUC } 2 \mathrm{hr}\left(\mathrm{mg}^{*} \min / \mathrm{dL}\right)\end{array}$ & $\begin{array}{c}4 \mathrm{~g} \text { BTI320 } \\
\text { AUC } 2 \mathrm{hr}\left(\mathrm{mg}^{*} \mathrm{~min} / \mathrm{dL}\right)\end{array}$ & $\begin{array}{c}\Delta 4 \mathrm{~g} \mathrm{BTI320} \text { vs Placebo } \\
\left(\mathrm{mg}{ }^{*} \mathrm{~min} / \mathrm{dL}\right)\end{array}$ & $\begin{array}{c}\text { 8 g BTI320 } \\
\text { AUC } 2 \mathrm{hr}\left(\mathrm{mg}^{*} \mathrm{~min} / \mathrm{dL}\right)\end{array}$ & $\begin{array}{c}\Delta 8 \mathrm{~g} \text { BTI320 vs Placebo } \\
\left(\mathrm{mg}{ }^{*} \mathrm{~min} / \mathrm{dL}\right)\end{array}$ \\
\hline \multirow{3}{*}{$\begin{array}{l}\text { Low-dose Responders } \\
(\mathrm{N}=3)\end{array}$} & 1 & 16,973 & 15,255 & $-1,718$ & 20,685 & 3,713 \\
\hline & 13 & 13,103 & 12,600 & -503 & 17,708 & 4,605 \\
\hline & 15 & 17,700 & 16,583 & $-1,118$ & 20,460 & 2,760 \\
\hline \multirow{5}{*}{$\begin{array}{l}\text { High-dose Responders } \\
(\mathrm{N}=5)\end{array}$} & 4 & 16,403 & 21,173 & 4,770 & 16,215 & -188 \\
\hline & 8 & 17,873 & 21,353 & 3,480 & 17,805 & -68 \\
\hline & 9 & 15,098 & 16,283 & 1,185 & 14,738 & -360 \\
\hline & 16 & 15,743 & 24,450 & 8,708 & 15,503 & -240 \\
\hline & 17 & 17,580 & 17,685 & 105 & 17,153 & -428 \\
\hline \multirow{6}{*}{$\begin{array}{l}\text { Both-dose Responders } \\
(\mathrm{N}=6)\end{array}$} & 3 & 21,533 & 20,198 & $-1,335$ & 19,395 & $-2,138$ \\
\hline & 6 & 23,828 & 21,668 & $-2,160$ & 21,788 & $-2,040$ \\
\hline & 7 & 16,395 & 16,230 & -165 & 16,148 & -248 \\
\hline & 18 & 23,768 & 21,705 & $-2,063$ & 20,100 & $-3,668$ \\
\hline & 21 & 24,203 & 16,823 & $-7,380$ & 19,575 & $-4,628$ \\
\hline & 24 & 21,863 & 20,123 & $-1,740$ & 19,980 & $-1,883$ \\
\hline \multirow{3}{*}{ Non-responders $(\mathbf{N}=\mathbf{3})$} & 2 & 14,085 & 18,158 & 4,073 & 16,253 & 2,168 \\
\hline & 12 & 16,838 & 16,875 & 38 & 17,708 & 870 \\
\hline & 20 & 20,213 & 20,625 & 413 & 24,645 & 4,433 \\
\hline
\end{tabular}


in the placebo group. Interestingly, although postprandial glucose AUC reductions were also observed in the high dose $(8 \mathrm{~g})$ group, the magnitude of reduction did not differ with the placebo group [51]. Importantly, various factors such as meal content, rate of postprandial absorption, and frequency and extent of exercise may hinder doseresponse assessments and it is possible that additional benefits in terms of delaying glucose absorption in the GIT is not observed in the high dose group due to the apparent ceiling effect of BTI320. As such, we hypothesized that the low dose BTI320 (4 g) is the optimal dose in delaying glucose absorption in the GIT, effectively reducing postprandial glucose excursions in both prediabetic and diabetic populations. In contrast to the dose-dependent efficacy data, there did not appear to be any dose-dependent adverse events in these studies; hypoglycemia and GI effects were rare and mild in severity.

\section{Conclusion}

In summary, data from this study showed that BTI320, given 3 times daily immediately prior to each meal for 7 days, attenuated glucose excursions in Type 2 diabetics. The placebo group tended to have a higher postprandial excursion whereas those in the two BTI320 groups tended to have a lower postprandial excursion compared to their fasting state, suggesting that BTI320 is effective in limiting postprandial glucose increase. The magnitude of postprandial excursion reduction observed is larger for the $4 \mathrm{~g}$ compared to the $8 \mathrm{~g}$ group, suggesting that $4 \mathrm{~g}$ appears to be the optimal efficacious dosage for BTI320. Further, despite lowering PPGE, there were no episodes of hypoglycemia, unlike other oral hypoglycemics and insulin which is prevalent in Type 2 diabetics $(0.52$ [95\% CI $0.37-0.67)]$ ) and 0.33 [95\% CI $0.24-0.42]$ ), respectively [66].

Limitations to this study including the small sample size and the 'out-patient' setting of the study could potentially mask the true efficacy of BTI320. Nonetheless, understanding that not all subjects will respond similarly to any drug, further studies with larger numbers of Type 1, Type 2, and pre-diabetics are needed to support BTI320 as an adjunct to a diabetes treatment program.

In conclusion, our study met the primary endpoint of a decrease in PPG-AUC0-4 with either dose of BTI320 compared with placebo and supports the notion that BTI320 is safe and effective in controlling PPGE in T2DM. Despite the 'out-patient' setting and limited number of subjects, these results are consistent with previous studies with BTI320 in both healthy volunteers and Type 2 diabetics. Although there appears to be a trend towards low dose (4 g) BTI320 compared with placebo in reducing the rise in postprandial glucose, further work needs to be performed to understand the potential role of BTI320 as an adjunct to diabetes treatment in T2DM.

\section{References}

1. World Health Organization (WHO) (2016) Global report on diabetes. Available from: http://www.who.int/-diabetes/global-report/en/ Accessed 1-Feb-2020.

2. American Diabetes Association (2018) Statistics about diabetes. Overall numbers, diabetes and prediabetes. Available from http://www.diabetes.org/diabetesbasics/statistics/. Accessed 1-Feb-2020.

3. Wild S, Roglic G, Green A, Sicree R, King H (2004) Global prevalence of diabetes: Estimates for the year 2000 and projections for 2030. Diabetes Care 27: 1047-1053. [Crossref]

4. WHO (2006) Definition and diagnosis of diabetes mellitus and intermediate hyperglycemia: report of a WHO/IDF consultation. Available from: http://www.who. $\mathrm{int} /$ diabetes/publications/diagnose_-diabetes2006/en. Accessed 1-Feb-2020.

5. Brownrigg JRW, Hughes CO, Burleigh D, Karthikesalingam A, Patterson BO, et al. (2016) Microvascular disease and risk of cardiovascular events among individuals with type 2 diabetes: A population-level cohort study. Lancet Diab Endocrinol 4: 588-597. [Crossref]
6. American Diabetes Association (2018) Economic costs of diabetes in the US in 2017. Diabetes Care 41: 917-928. [Crossref]

7. American Diabetes Association (2018) Classification and diagnosis of diabetes Standards of medical care in diabetes - 2018. Diabetes Care 41: S13-S27.[Crossref]

8. Buysschaert M, Medina JL, Buysschaert B, Bergman M (2016) Definitions (and current controversies) of diabetes and prediabetes. Curr Diabetes Rev 12: 8-13. [Crossref]

9. Yang G, Li C, Gong Y, Li J, Cheng X, et al. (2013) A prospective, randomized, openlabel study comparing the efficacy and safety of pre-prandial and prandial insulin in combination with acarbose in elderly, insulin-requiring patients with type 2 diabetes mellitus. Diabetes Technol Ther 15: 513-519. [Crossref]

10. World Health Organization (WHO) (2003) Diet, nutrition, and the prevention of chronic diseases. World Health Organ Tech Rep, Ser 916: i-viii, 1-149.

11. Phillips LS, Ratner RE, Buse JB, Kahn SE (2014) We can change the natural history of type 2 diabetes. Diabetes Care 37: 2668-2676. [Crossref]

12. Sheard NF, Clark NG, Brand-Miller JC, Franz MJ, Pi-Sunyer FX, et al. (2004) Dietary carbohydrate (amount and type) in the prevention and management of diabetes. A statement by the American Diabetes Association. Diabetes Care 27: 2266-2271. [Crossref]

13. Smith-Palmer J, Brändle M, Trevisan R, Osini Frederici M, Liabat S, et al. (2014) Assessment of the association between glycemic variability and diabetes-related complications in type 1 and type 2 diabetes. Diabetes Res Clin Pract 105: 273-284. [Crossref]

14. Mikkila V, Rasanen L, Laaksonen MM, Juonala M, Viikari J, et al. (2009) Long-term dietary patterns and carotid artery intima media thickness: the cardiovascular risk in young Finns study. Br J Nutr 102: 1507-1512. [Crossref]

15. Hodge AM, English DR, O'Dea K, Giles GG (2007) Dietary patterns and diabetes incidence in the Melbourne Collaborative Cohort Study. Am J Epidemiol 165: 603610. [Crossref]

16. O'Keefe JH, Gheewala NM, O'Keefe JO (2008) Dietary strategies for improving postprandial glucose, lipids, inflammation, and cardiovascular health. J Am Coll Cardiol 51: 249-255. [Crossref]

17. Blaak EE, Antoine J-M, Benton D, Björck I, Bozzetto L et al (2012) Impact of postprandial glycaemia on health and prevention of disease. Obes Rev 13: 923-984. [Crossref]

18. Wolever TMS, Bolognesi C (1996) Source and amount of carbohydrate affect postprandial glucose and insulin in normal subjects. J Nutr 126: 2798-2806. [Crossref]

19. Crapo PA, Kolterman OG, Waldeck N, Reaven GM, Olefsky JM (1980) Postprandial hormonal responses to different types of complex carbohydrates in individuals with impaied glucose tolerance. Am J Clin Nutr 33: 1723-1728. [Crossref]

20. Von Bibra H, Wulf G, St John Sutton M, Pfützner A, Schuster T, et al. (2014) Lowcarbohydrate/high-protein diet improves diastolic cardiac function and the metabolic syndrome in overweight-obese patients with type 2 diabetes. IJC Metabol Endocrin 2: $11-18$.

21. Lansink M, van Laere KM, Vendrig L, Rutten GE (2011) Lower postprandial glucose responses at baseline and after 4 weeks of a diabetes-specific formula in diabetes type 2 patients. Diab Res Clin Pract 93: 421-429. [Crossref]

22. Laksir H, Lansink M, Regueme SC, de Vogel-van den Bosch J, Pfeiffer AFH, et al (2017) Glycaemic response after intake of a high energy, high protein, diabetes-specific formula in older malnourished or at risk of malnutrition type 2 diabetes patients. Clin Nutr 37: 2084-2090. [Crossref]

23. Hussain TA, Mathew TC, Dashti AA, Asfar S, Al-Zaid N, et al. (2012) Effect of lowcalorie versus low-carbohydrate ketogenic diet in type 2 diabetes. Nutrition 28: 10161021. [Crossref]

24. Shukla AP, Andono J, Touhamy SH, Casper A, Iliescu RG, et al. (2017) Carbohydratelast meal pattern lowers postprandial glucose and insulin excursions in type 2 diabetes. BMJ Open Diab Res Care 5: e0004440. [Crossref]

25. Wolever TMS, Gibbs AL, Chiasson J-L, Connelly PW, Josse RG, et al. (2013) Altering course or amount of dietary carbohydrate has acute and chronic effects of postprandial glucose and triglycerides in type 2 diabetics: Canadian trial of Carbohydrates in Diabetes (CCD). Nutr Metab Cardiovasc Dis 23: 227-234. [Crossref]

26. Liebman M (2014) When and why carbohydrate reduction can be a viable option. Nutrition 30: 748-754. [Crossref]

27. Tay J, Luscombe-Marsh ND, Thompson CH, Noakes M, Buckley JD, et al. (2014) A very low-carbohydrate, low-saturated fat diet for type 2 diabetes management: A randomized trial. Diabetes Care 37: 2909-2918. [Crossref] 
28. Clifton PM, Condo D, Keogh JB (2014) Long term weight maintenance after advice to consume low carbohydrate, higher protein diets - A systemic review and metaanalysis. Nutr Metab Cardiovasc Dis 24: 224-235. [Crossref]

29. Wolever TMS, Chiasson J-L, Josse RG, Leiter LA, Maheux P, et al. (2017) Effects of changing the amount and source of dietary carbohydrates on symptoms and dietary satisfaction over a 1-year period in subjects with type 2 diabetes: Canadian Trial of Carbohydrates in Diabetes (CCD). Can J Diabetes 41: 164-176. [Crossref]

30. Naude CE, Schoonees A, Senekal M, Young T, Garner P, et al. (2014) Low carbohydrate versus isoenergetic balanced diets for reducing weight and cardiovascular risk: A systematic review and meta-analysis. PLoS One 9: e100652. [Crossref]

31. Brouns F (2018) Overweight and diabetes prevention: Is a low-carbohydrate-high-fat diet recommendable? Eur J Nutr 57: 1301-1312. [Crossref]

32. Feinman RD, Pogozelski WK, Astrup A, Bernstein RK, Fine EJ, et al. (2015) Dietary carbohydrate restriction as the first approach in diabetes management: Critical review and evidence base. Nutrition 31: 1-13. [Crossref]

33. Meng Y, Bai H, Wang S, Li Z, Wang Q, et al. (2017) Efficacy of a low carbohydrate diet for type 2 diabetes mellitus management: A systematic review and meta-analysis of randomized controlled trials. Diab Res Clin Pract 131: 124-131. [Crossref]

34. Pearce KL, Noakes M, Keogh J, Clifton PM (2008) Effect of carbohydrate distribution on postprandial [glucose peaks with the use of continuous glucose monitoring in type 2 diabetics. Am J Clin Nutr 87: 638-644. [Crossref]

35. Meigs JB, Nathan DM, D'Agostino Sr RB, Wilson PW (2002) Fasting and postchallenge glycemia and cardiovascular disease risk: the Framingham Offspring Study. Diabetes Care 25: 1845-1850. [Crossref]

36. Luke DR, Lee KKY, Rausch CW, Cheng C (2018) Phase 1 study of the pharmacology of BTI320 before high-glycemic meals. Clin Pharmacol Drug Dev 8: 395-403. [Crossref]

37. Trask LE, Kasid N, Homa K, Chaidarun S (2013) Safety and efficacy of the nonsystemic chewable complex carbohydrate dietary supplement PAZ320 on postprandial glycemia when added to oral agents or insulin in patients with type 2 diabetes mellitus. Endocrinol Pract 19: 627-632. [Crossref]

38. Trask LE, Chaidarun SS, Platt D, Parkin CG (2014) Treatment with a nove galactomannan derivative reduces 2-hour prostprandial glucose excursions in individuals with type 2 diabetes treated with oral medications and/or insulin. J Diabetes Sci Technol 8: 1018-1022. [Crossref]

39. WMA (World Medical Association) (1997) Declaration of Helsinki. Recommendations guiding physicians in biomedical research involving human subjects. JAMA 277: 925926. [Crossref]

40. American Diabetes Association (2011) Standards of medical care in diabetes 2011 Diabetes Care 34: S11-S61. [Crossref]

41. Levey AS, Bosch JP, Lewis JB, Greene T, Rogers N, et al. (1999) A more accurate method to estimate glomerular filtration rate from serum creatinine: a new prediction equation. Modification of Diet in Renal Disease Study Group. Ann Intern Med 130: 461-470. [Crossref]

42. Trask LE, Kasid N, Homa K, Chaidarun S (2013) Safety and efficacy of the nonsystemic chewable complex carbohydrate dietary supplement PAZ320 on postprandial glycemia when added to oral agents or insulin in patients with type 2 diabetes mellitus. Endocrinol Pract 19: 627-632. [Crossref]

43. Snapinn SM, Jiang Q (2007) Responder analyses and the assessment of a clinically relevant treatment effect. Trials 8:31. [Crossref]

44. Lin Y (2016) Robust inference for responder analysis: Innovative clinical trial design using a minimum p-value approach. Contemp Clin Trials Commun 3: 65-69. [Crossref]

45. Tai MM (1994) A mathematical model for the determination of total area under glucose tolerance and other metabolic curves. Diabetes Care 17: 152-154. [Crossref]

46. Monnier L, Colette C, Owens D (2011) Postprandial and basal glucose in type 2 diabetes: assessment and respective impacts. Diab Technol Therapeut 13: S25-32: [Crossref]
47. Troisi RJ, Cowie CC, Harris MI (2000) Diurnal variation in fasting plasma glucose. Implications for diagnosis of diabetes in patients examined in the afternoon. JAMA 284: 3157-3159. [Crossref]

48. Ceriello A (2005) Postprandial hyperglycemia and diabetes complications. Is it time to treat? Diabetes 54: 1-7. [Crossref]

49. Kearney ML, Thyfaukt JP (2016) Exercise and postprandial glycemic control in Type 2 diabetes. Curr Diabetes Rev 12: 199-210. [Crossref]

50. Kim SR, Lee YH, Lee SG, Kang ES, Cha BS, et al. (2016) Urinary N-acety-ß-Dglucosaminidase, an early marker of diabetic kidney disease, might reflect glucose excursion in patients with type 2 diabetes. Medicine 95: e4114. [Crossref]

51. Luk AOY, Zee BCY, Chong M, Ozaki R, Rausch CW, et al. (2018) A proof-of-concep study to evaluate the efficacy and safety of BTI320 on post-prandial hyperglycemia in Chinese subjects with pre-diabetes. BMC Endocr Disord 18: 59. [Crossref]

52. Khazrai YM, Defeudis G, Pozzilli P (2014) Effect of diet on type 2 diabetes mellitus: a review. Diabetes Metab Res Rev 30: 24-33. [Crossref]

53. Landa-Anell MV, Melgarejo-Hernández MA, Garcia-Ulloa AC, Del Razo-Olvera FM, Velázquez-Jurado HR, et al. (2019) Barriers to adherence to a nutritional plan and strategies to overcome them in patients with type 2 diabetes mellitus: results after two years of follow-up. Endocrinol Diabetes Nutr 67: 4-12. [Crossref]

54. Burford SJ, Park S, Dawda P (2019) Small data and its visualization for diabetes selfmanagement: Qualitative study. JMIR Diabetes 4: e10324. [Crossref]

55. Béjar LM, Garcia-Perea MD, Resyes ÓA, Vázquez-Limón E (2019) Relative validity of a method based on a smartphone app (electronic 12-hour dietary recall) to estimate habitual dietary intake in adults. JMIR Mhealth Uhealth 7: e11531. [Crossref]

56. Myhre JB, Johansen AMW, Hjartåker A, Andersen LF (2018) Relative validation of a pre-coded food diary in a group of Norwegian adults - Comparison of underreporters and acceptable reporters PLoS One 13: e0202907. [Crossref]

57. Lemacks JL, Adams K, Lovetere A (2019) Dietary intake reporting accuracy of the Bridge2U mobile application food log compared to control meal and dietary recall methods. Nutrients 11: pii- E199 [Crossref]

58. Endrenyi L, Yan W (1993) Variation of Cmax and Cmax/AUC in investigations of bioequivalence. Int J Clin Pharmacol Ther Toxicol 31: 184-189. [Crossref]

59. Crapo PA, Reaven G, Olefsky J (1977) Post-prandial plasma-glucose and -insulin responses to different complex carbohydrates. Diabetes 26: 1178-1183.

60. Harris WS, Windsor SL, Newton FA, Gelfand RA (1997) Inhibition of cholesterol absorption with CP-148,623 lowers serum cholesterol in humans. Clin Pharmacol Ther 61: 385-389. [Crossref]

61. Morehouse LA, Bangerter F-W, DeNinno MP, Inskeep PB, McCarthy PA, et al. (1999) Comparison of synthetic saponin cholesterol absorption inhibitors in rabbits: evidence for a non-stoichiometric, intestinal mechanism of action. J Lipid Res 40: 464-474 [Crossref]

62. Heřmánková E, Žák A, Poláková L, Hobzová R, Hromádka R, et al. (2018) Polymeric bile acid sequestrants: Review of design, in vitro binding activities, and hypocholesterolemic effects. Eur J Med Chem 144: 300-317. [Crossref]

63. Van de Laar F, Lucassen PLBJ, Akkermans RP, Van de Lisdonk EH, Rutten GEHM, et al. (2005) Alpha-glucosidase inhibitors for type 2 diabetes mellitus. Cochrane Database Syst Rev 18: CD003639. [Crossref]

64. Charmot D (2012) Non-systemic drugs: A critical review. Curr Pharmaceut Des 18 1434-1445. [Crossref]

65. Coniff RF, Shapiro JA, Seaton TB (1994) Long-term efficacy and safety of acarbose in the treatment of obese subjects with non-insulin-dependent diabetes mellitus. Arch Intern Med 154: 2442-2448. [Crossref]

66. Edridge CL, Dunkley AJ, Bodicoat DH, Rose TC, Gray LJ et al. (2015) Prevalence and incidence of hypoglycaemia in 532,542 people with Type 2 diabetes on oral therapies and insulin: A systematic review and meta-analysis of population-based studies. PLoS One 10: e0126427. [Crossref]

Copyright: (C2020 Luke DR. This is an open-access article distributed under the terms of the Creative Commons Attribution License, which permits unrestricted use, distribution, and reproduction in any medium, provided the original author and source are credited. 